\title{
IDENTIFIKASI PERCEPATAN TANAH MAKSIMUM (PGA) DAN ERENTANAN TANAH MENGGUNAKAN METODE MIKROTREMOR I JALUR SESAR KENDENG
}

\author{
Anindya Putri R. , M. Singgih Purwanto, Amien Widodo \\ Teknik Geofisika, Fakultas Teknik Sipil dan Perencanaan, Institut Teknologi Sepuluh Nopember \\ Putrianindya18@gmail.com
}

\begin{abstract}
Abstrak. Penelitian yang bertujuan untuk memprediksi kapan, dimana dan berapa kekuatan gempa bumi dapat diketahui dengan menganalisa data mikrotremor yang berguna untuk mengidentifikasi PGA di daerah yang dilewati sesar Surabaya, sehingga nantinya didapatkan peta Peak Ground Acceleration atau PGA. Selain itu dilakukan pula analisa kerentanan tanah akibat gempa bumi yang nantinya didapatkan peta kerentanan seismic yang menggambarkan tingkat kerawanan terhadap gempa bumi untuk keperluan rencana tata ruang dan wilayah maupun konstruksi bangunan tahan gempa. Data mikrotremor dianalisis dengan metode HVSR dengan software Easy HVSR untuk mendapatkan nilai Ao dan Fo yang nantinya digunakan untuk perhitungan Kg. Sedangkan pada pengukuran PGA didapatkan dari rumus atenuasi Fukusima dan Tanaka yang parameternya berupa jarak, Magnitute, dan parameter sumber gempa yaitu sesar Surabaya-Kendeng dan Surabaya-Waru. Dari pengolahan data didapatkan nilai Amplifikasi rata-rata sebesar 2.8. Nilai fo rata-rata adalah sebesar $1.7 \mathrm{~Hz}$. Nilai Kg terendah adalah sebesar 7.7. Nilai PGA terhadap batuan dasar berdasarkan sesar Surabaya-Kendeng terbesar adalah $4.3 \mathrm{~g}$, sedangkan berdasarkan sesar Surabaya-Waru nilai PGA terhadap batuan dasar terbesar adalah sebesar 0.9g.

Kata Kunci-PGA, Kg, Ao, Fo, Metode HVSR
\end{abstract}

\begin{abstract}
This study purposed to predict when, where and how much earthquake strength can be identified by analyzing microtremor data useful for identifying PGA in the area passed by the fault of Surabaya, that is obtained a map Peak Ground Acceleration or PGA. Besides that, seismic vulnerability analysis due to earthquake will be obtained seismic vulnerability map that describes the level of vulnerability to earthquakes for spatial and regional planning purposes as well as earthquake resistant building construction. Microtremor data were analyzed by HVSR method with Easy HVSR software to obtain Ao and fo values which will be used for Kg calculation. While the measurement of PGA obtained from the attenuation formula Fukusima and Tanaka whose parameters such as distance, magnitude, and parameters of earthquake sources ie fault Surabaya-Kendeng and Surabaya-Waru. From the data processing got the average Amplification value of 2.8. The average fo value is $1.7 \mathrm{~Hz}$. The lowest $\mathrm{Kg}$ value is 7.7. The value of PGA to bedrock based on the largest Surabaya-Kendeng fault is $4.3 \mathrm{~g}$, whereas based on the Surabaya-Waru fault the PGA value against the largest bedrock is $0.9 \mathrm{~g}$.
\end{abstract}

Keywords: PGA, Kg, Ao, Fo, HVSR method

\section{PENDAHULUAN}

Secara geografis, Negara Indonesia memiliki potensi besar sebagai Negara yang sering mengalami gempa bumi. Pada tahun 2016 PUSGEN atau Pusat Studi Gempa Nasional menemukan fakta bahwa letak Surabaya secara geografis berada pada dua patahan bumi yang diperkirakan masih aktif dan diduga suatu saat besar kemungkinan bisa menimbulkan gempa bumi dengan kekuatan besar diwilayah Surabaya. Patahan tersebut adalah sesar Kendeng dan sesar Waru. Telah kita ketahi bahwa dampak dari adanya gempa bumi adalah tingkat kerusakan yang ditimbulkan dari suatu gempa bumi sangat bergantung pada kondisi topografi dan geologi permukaan. Menurut hasil penelitian, patahan atau sesar tersebut membelah Surabaya menjadi dua bagian yaitu utara dan selatan. Usaha untuk memprediksi kapan, dimana dan berapa kekuatan gempa bumi sampai saat ini masih belum tepat, maka usaha yang paling baik untuk diupayakan adalah dengan cara mitigasi bencana gempa bumi untuk mengkaji rencana tata ruang dan wilayah. maka dilakukan penelitian ini untuk menganalisa data mikrotremor yang berguna untuk 
mengidentifikasi PGA di daerah yang dilewati sesar Kendeng di daerah Surabaya, sehingga nantinya didapatkan peta Peak Ground Acceleration atau PGA. Selain itu dilakukan pula analisa kerentanan tanah akibat gempa bumi yang nantinya didapatkan pula peta kerentanan tanah. Peta tersebut menggambarkan tingkat kerawanan terhadap gempa bumi untuk keperluan rencana tata ruang dan wilayah maupun konstruksi bangunan tahan gempa

\section{TINJAUAN PUSTAKA}

\section{Periode Predominan Tanah}

Dalam mencari nilai percepatan tanah di suatu tempat, perlu digunakan nilai periode dominan tanah di tempat itu, berdasarkan hubungan:

$$
T=\frac{1}{f}
$$

dengan adalah periode (s), dan adalah frekuensi $(\mathrm{Hz})$ maka nilai periode dominan tanah di suatu tempat dapat dicari dengan mencari nilai frekuensi predominannya terlebih dahulu. Untuk mencari nilai frekuensi predominan tanah, bisa digunakan teknik Horizontal to Vertical Spectral Ratio (HVSR). Kondisi tanah setempat mempengaruhi karakteristik gelombang gempabumi selama gempabumi terjadi.

\section{Horizontal to Vertical Spectral Ratio}

Metode HVSR pertama kali diperkenalkan oleh Nogoshi dan Iragashi (1971) yang menyatakan adanya hubungan antara perbandingan komponen horizontal dan vertikal terhadap kurva eliptisitas pada gelombang Rayleigh yang kemudian disempurnakan oleh Nakamura (1989) yang menyatakan bahwa perbandingan spectrum $\frac{\boldsymbol{H}}{\boldsymbol{V}}$ sebagai fungsi frekuensi berhubungan erat dengan fungsi site transfer. Faktor amplifikasi dari komponen horizontal dan vertikal pada permukaan tanah yang bersentuhan langsung dengan batuan dasar di area cekungan dilambangkan dengan $T_{H}$ dan $T_{V}$.

Persamaan diatas menjadi dasar perhitungan rasio spektrum mikrotremor komponen horizontal terhadap komponen vertikalnya atau Horizontal to Vertical Spectral Ratio (HVSR) sebagai berikut:

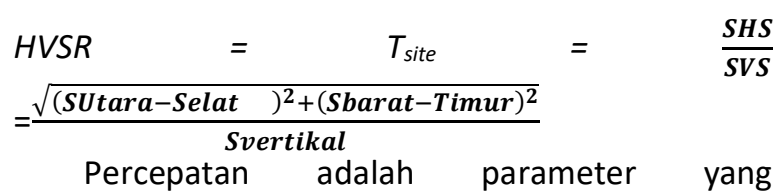
menyatakan perubahan kecepatan mulai dari keadaan diam sampai pada kecepatan tertentu.
Percepatan getaran tanah merupakan gangguan yang dikaji untuk setiap gempabumi, kemudian dipilih percepatan tanah maksimum atau Peak Ground Acceleration (PGA) untuk dipetakan agar bisa memberikan pengertian tentang efek paling parah yang pernah dialami suatu lokasi.

Percepatan getaran tanah maksimum adalah nilai percepatan getaran tanah yang terbesar yang pernah terjadi di suatu tempat yang diakibatkan oleh gempabumi. Semakin besar nilai PGA yang pernah terjadi disuatu tempat, semakin besar bahaya dan resiko gempabumi yang mungkin terjadi. Percepatan tanah adalah faktor utama yang mempengaruhi konstruksi bangunan dan menimbulkan momen gaya yang terdistribusikan merata di titik-titik bangunan, sehingga percepatan tanah merupakan titik tolak perhitungan bangunan tahan gempa.

\section{Amplifikasi}

Amplifikasi merupakan perbesaran gelombang tanah yang terjdi akibat adanya perbedaan yang signifikan antar lapisan, dengan kata lain gelombang tanah mengalami perbesaran jika merambat pada suatu medium ke medium lain yang lebih lunak dibandingkan dengan medium awal yang dilaluinya. Semakin besar perbedaan itu, maka perbesaran yang dialami gelombang tersebut akan semakin besar. Hal ini dinyatakan juga oleh Nakamura dmana nilai faktor penguatan (amplifikasi) tanah berkaitan dengan perbandingan kontras impedansi lapisan permukaan dengan lapisan di bawahnya. Bila perbandingan kontras impedansi kedua lapisan tersebut tinggi maka nilai penguatan juga tinggi, begitu pula sebaliknya. Marjiyono (2010) menyatakan bahwa, amplifikasi berbanding lurus dengan nilai perbandingan spectral horizontal dan vertikalnya $(H / V)$. nilai amplifikasi bisa bertambah jika batuan telah mengalami deformasi (pelapukan, pelipatan atau peseseran) yang mengubah sifat fisik batuan.

\section{Indeks Kerentanan Tanah}

Indeks kerentanan Tanah (Kg) merupakan indeks yang menggambarkan tingkat kerentanan lapisan tanah permukaan terhadap deformasi saat terjadi gempabumi. Indeks kerentanan tanah didapat dari pergeseran regangan permukaan tanah dan strukturnya saat terjadi gempabumi. Menurut Nakamura, kerusakan yang diakibatkan oleh gempabumi terjadi pada saat gaya gempa bumi 
melebihi batas dari regangan (strain) sehingga terjadi deformasi lapisan tanah permukaan.Pada kondisi regangan, indeks kerentanan tanah dapat didefinisikan dalam skala $10-6 /(\mathrm{cm} / \mathrm{s} 2)$. Dalam penentuan indeks kerentanan tanah perlu diperhatikan shear strain pada permukaan tanah. Dalam penentuan nilai indeks kerentanan tanah suatu daerah, faktor-faktor kondisi geologi daerah setempat perlu dipertimbangkan. Tingkat indeks kerentanan tanah yang tinggi biasanya ditemukan pada daerah dengan frekuensi resonansi yang rendah.

$$
K g=\frac{A g^{2}}{f g} \frac{1}{\pi^{2} v b}
$$

\section{DETERMINISTIC SEISMIK HAZARD ANALYSIS}

Salah satu metoda analisa resiko gempa adalah metoda Deterministic Seismic Hazard Analysis (DSHA), dimana dalam metoda ini evaluasi dari gerakan tanah (ground motion) untuk suatu wilayah didasarkan kepada skenario gempa wilayah tersebut. Skenario gempa ini berisi tentang kejadian gempa dengan besar (magnitude) tertentu yang akan terjadi pada lokasi tertentu.

\section{ATENUASI FUKUSIMA DAN TANAKA}

Instrumentasi kegempaan dapat mengukur Fungsi atenuasi ini dikembangkan untuk percepatan maksimum horizontal yang berlaku pada sumber gempa di sekitar Jepang. Data yang digunakan terdiri dari 1372 komponen percepatan tanah maksimum horizontal dari 28 gempa yang terjadi di Jepang dan 15 gempa yang terjadi di Amerika serta di negara lain. Model atenuasi yang digunakan untuk menghitung bagaimana penyebaran geometrik dari gelombang gempa. Beberapa peneliti dari Indonesia menganjurkan penggunaan persamaan ini untuk patahan (fault) permukaan yang ada di Sumatera dan Jawa. Persamaan empiris dari persamaan fungsi atenuasi ini adalah:

LOGAmax $=1.30+0.41 \mathrm{MS}-\log [R+0.032 \times 100.41 \mathrm{MS}]-0.0034 R$ dimana:

MS = magnitude gelombang permukaan

$\mathrm{R}=$ jarak terdekat dari lokasi ke sumber gempa $(\mathrm{km})$ secara objektif kuantitatif besarnya gempa, yang disebut magnitude gempa.

\section{METODOLOGI PENELITIAN}

Pada penelitian ini, data yang digunakan adalah:

a. Data mikrotremor primer sebanyak 14 data (X01X14)

b. Data mikrotremor sekunder sebanyak 99 data.

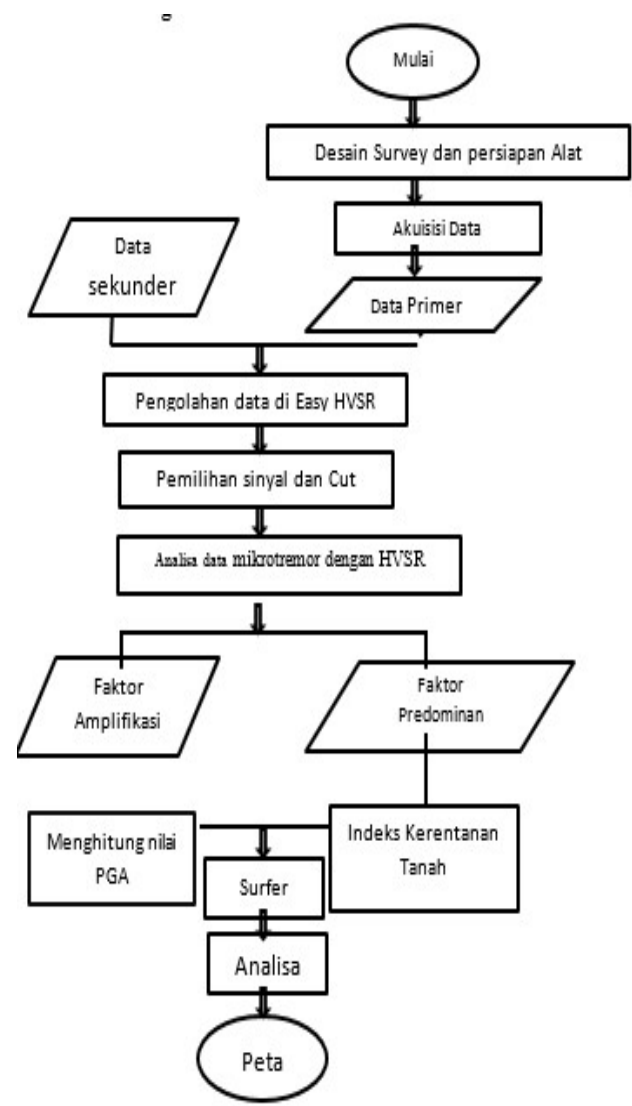

Gambar 1. Diagram Alir Penelitian.

Penelitian diawali dengan melakukan pengolahan data mikrotremor menggunakan software easy HVSR yang bertujuan untuk mendapatkan nilai Fo dan Ao yang selanjutnya nilai tersebut diinputkan kedalam rumus $\mathrm{Kg}$ (Kerentanan Tanah) sehingga didapatkan nilai Kg yang dicari. Untuk mendapatkan nilai PGA permukaan, dilakukan secara deterministic rumus atenuasi Fukushima dan Tanaka yang berdasarkan parameter-parameter yaitu pertama identifikasi dan karakterisasi sumber gempa yang mempunyai kapasitas menghasilkan gerakan tanah di suatu lokasi, Kedua Kedua dibutuhkan parameter jarak terdekat dari sumber gempa ke titik pengukuran, Ketiga merupakan penentuan nilai magnitude gempa yang nilainya telah diketahui yaitu sebesar 4.6 dan 5.6 Ms. Untuk mendapatkan nilai PGA permukaan, maka diperlukan nilai Ao (amplifikasi) yang didapatkan dari pengolahan data yang telah dilakukan. lalu didapatkan nilai PGA permukaa dengan cara mengalikan nilai Amax yang didapatkan dengan nilai Ao (Amplifikasi). Nilai Amax didapatkan dari menginputkan nilai Ao dan Fo yang didapatkan pada rumus fungsi atenuasi Fukushima dan Tanaka. 


\section{HASIL DAN ANALISA}

Mikrotremor merupakan getaran tanah yang sangat kecil dan terus menerus yang bersumber dari berbagai macam getaran seperti, lalu lintas, angin, aktivitas manusia dan lain-lain. Lang mendefinisikan mikrotremor sebagai noise periode pendek yang berasal dari sumber artifisial. Gelombang ini bersumber dari segala arah yang saling beresonansisi. Mikrotremor dapat juga diartikan sebagai getaran harmonik alami tanah yang terjadi secara terus menerus, terjebak dilapisan sedimen permukaan, terpantulkan oleh adanya bidang batas lapisan dengan frekuensi yang tetap, disebabkan oleh getaran mikro di bawah permukaaan tanah dan kegiatan alam lainnya. Karakteristik mikrotremor mencerminkan karakteristik batuan di suatu daerah. Penelitian mikrotremor juga banyak dilakukan pada studi penelitian struktur tanah (soil investigation) untuk mengetahui keadaan bawah permukaan tanah (Syaifuddin F dkk, 2016). Penelitian mikrotremor dapat mengetahui karakteristik lapisan tanah berdasarkan parameter periode dominannya dan faktor penguatan gelombangnya (amplifikasi).

Dalam kajian teknik kegempaan, litologi yang lebih lunak mempunyai resiko yang lebih tinggi bila digoncang gelombang gempabumi, karena mengalami penguatan (amplifikasi) gelombang yang lebih besar dibandingkan dengan batuan yang lebih kompak. Sejak Omori mengamati mikrotremor untuk pertama kalinya tahun 1908 , banyak para ahli seismologi dan insinyur teknik gempabumi menyelidiki mikrotremor baik dari segi ilmiah maupun terapannya, sebab kegunaan mikrotremor banyak sekali, diantaranya:

1. Mikrotremor berguna untuk mengklasifikasikan jenis tanah berdasarkan periode dominan yang harganya spesifik untuk tiap jenis tanah, sebab tanggapan bangunan terhadap getaran gempabumi sebagian besar bergantung pada komposisi tanah di tempat bangunan berdiri.

2. Dari penyelidikan di Jepang telah ditetapkan bahwa mikrotremor digunakan tidak hanya sebagai alat untuk mengantisipasi sifat gerakan gempabumi tetapi juga untuk membuktikan koefisien gaya yang telah ditetapkan dalam perencanaan bangunan tahan gempa.

3. Menjelaskan struktur bawah permukaan tanah di tempat mikrotremor diamati.

\section{Analisa Frekuensi dominan tanah}

Nilai frekuensi dominan atau fo di suatu tempat dapat digunakan untuk perencanaan bangunan tahan gempa sebagai keperluan mitigasi bencana gempa bumi. Nilai fo yang rendah bukan hanya menunjukkan adanya akibat dari efek resonansi, melainkan dapat meningkatkan kerentanan terhadap bahaya dengan periode yang panjang.

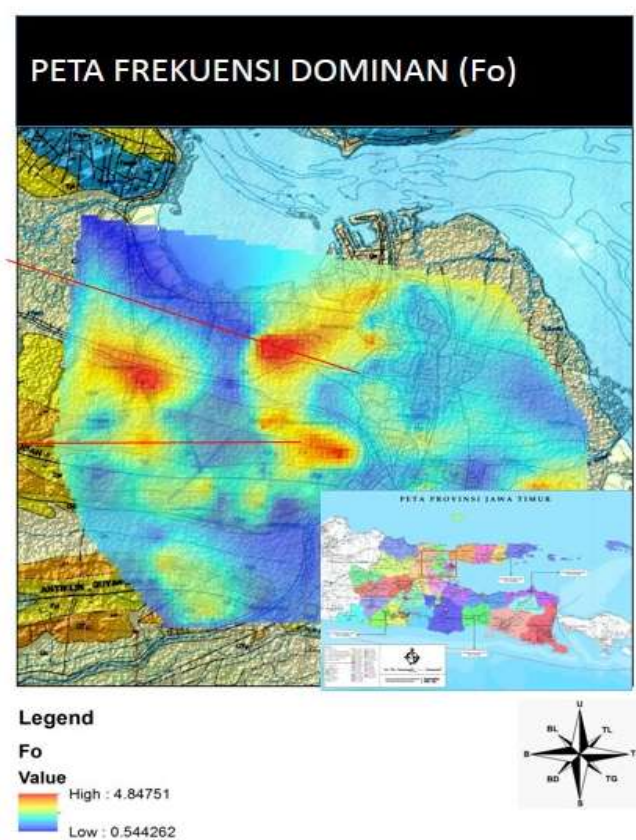

Gambar 2 Peta Frekuensi dominan (fo) hasil pengolahan data

Rentang nilai frekuensi yang didapatkan adalah berkisar dari $0.8 \mathrm{~Hz}$ hingga $5.1 \mathrm{~Hz}$. Nilai frekuensi yang mendominasi ada sekitar $1.1 \mathrm{~Hz}$ hingga $2.8 \mathrm{~Hz}$. Dari peta penampang yang didapatkan terlihat persebaran frekuensi dominan yang tidak merata, bagian yang berwarna biru tua memiliki nilai fo paling kecil. Sedangkan nilai fo yang mendominasi ditunjukkan dengan warna biru muda hingga kuning yang persebarannya cukup merata di titik pengamatan. Nilai fo yang berada pada rentan nilai $3.6 \mathrm{~Hz}$ hingga $4.4 \mathrm{~Hz}$ merupakan nilai yang tergolong tinggi, rentan nilai tersebut berada pada antara sesar Surabaya-kendeng dan Surabaya-Waru. Sedangkan nilai tertinggi yaitu 5.1 yang dihasilkan dari titik SBY34 berada tepat di sesar SurabayaKendeng. Berdasarkan peta geologi Surabaya, diketahui bahwa wilayah Surabaya berada pada Tipe III yang diklasifikasikan oleh Kanai yaitu berupa jenis III pada frekuensi sekitar 2.5-4 $\mathrm{Hz}$ yang berupa batuan alluvial, dengan ketebalan lebih dari $5 m$ yang terdiri dari sandy-gravel. Sandy hard clay, loam, dll. 


\section{Analisa Amplifikasi}

Besaran dari amplifikasi dapat diestimasi dari kontras parameter perambatan gelombang pada bedrock dan sedimen permukaan. Semakin besar perbedaan parameter, semakin besar pula niai amplifikasi perambatan gelombangnya. Berdasarkan pengolahan data mikrotremor dengan HVSR didapatkan nilai Fo dan juga Ao. Didapatkan nilai Ao atau amplifikasi berada pada rentan nilai $1.1-8.7$. Nilai tersebut bervariasi dari keseluruhan data yang dilakukan pengolahan. Namun terlihat pada gambar dibawah ini persebarannya cukup merata, hanya saja pada beberapa titik memiliki nilai amplifikasi atau Ao yang cukup besar.

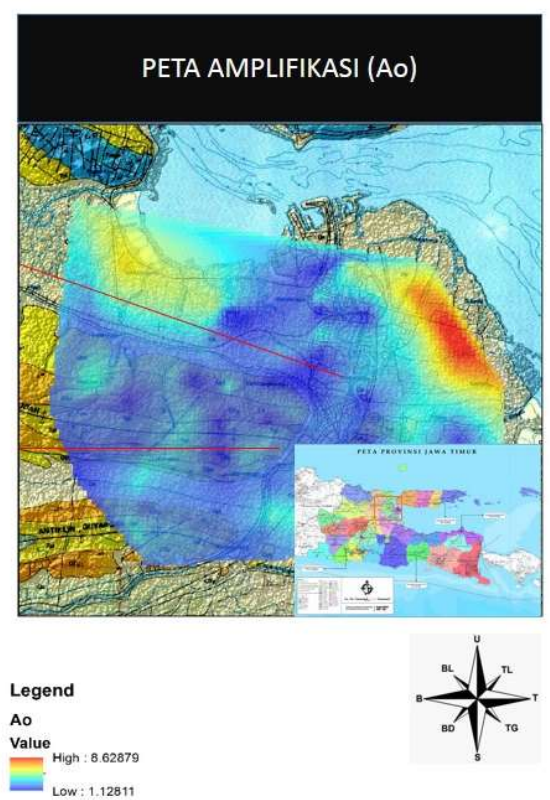

Gambar 3 Peta Amplifikasi (Ao) hasil pengolahan data

Terlihat bahwa nilai Ao yang mendominasi adalah warna biru yang memiliki nilai antara 1.5 hingga 4. Namun terdapat nilai yang tergolong sangat besar yaitu yang ditunjukkan dengan warna merah yaitu memiliki nilai $>8$ yang berada pada bagian ujung atau timur laut daerah penelitian. Akan tetapi pada asalnya letaknya sudah dominan dibagian selatan. Bila dilihat dari nilai amplifikasi yang didapatkan dari pengolahan data adalah berkisar antara 1.5 - 4 maka dapat diklasifikasikan tergolong pada zona 2 yaitu pada rentan $3 \leq A<6$ yaitu pada kategori sedang.

\section{Analisa Indeks Kerentanan Tanah (Kg)}

Nilai yang didapatkan dari perhitungan $\mathrm{Kg}$ dapat digunakan untuk mendeteksi zona lemah (unconsolidated sediment) atau daerah atau wilayah yang berpotensi akan terjadi kerusakan dan rekahan tanah apabila terjadi gempa bumi. Semakin tinggi nilai indeks kerentanan tanah atau $\mathrm{Kg}$ didaerah tersebut, maka tingkat jumlah kerusakan bangunan yang ditimbulkan akibat gempa bumi semakin tinggi. Hal ini dapat terjadi karena semakin tinggi nilai indeks kerentanan tanah suatu daerah maka tingkat kestabilan struktur tanah pada daerah tersebut semakin rendah, maka apabila terjadi guncangan gempa bumi kemungkinan kerusakan bangunan yang ditimbulkan semakin tinggi.

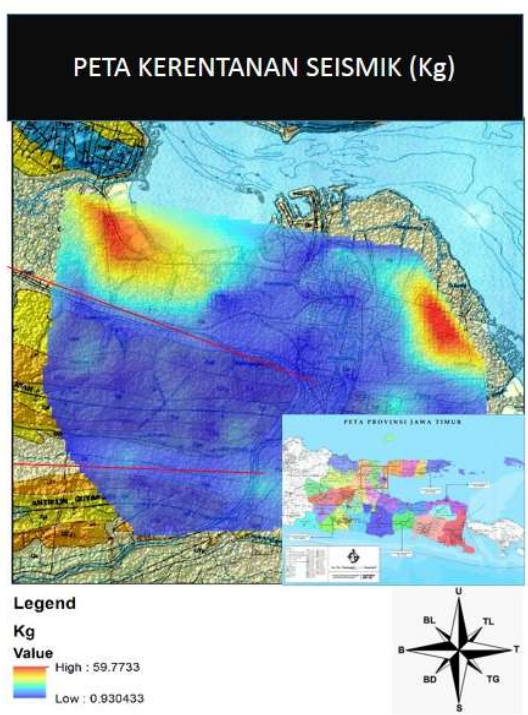

Gambar 4. Peta Kerentanan tanah (Kg) hasil pengolahan data.

Berdasarkan peta indeks kerentanan seismic diatas, didapatkan nilai tertinggi adalah sebesar 60 $\mathrm{cm} / \mathrm{s}^{2}$ yaitu pada titik T19 yang ditunjukkan dengan warna merah pekat. Persebaran warna merah pekat hanya pada arah timur laut dari daerah penelitian. Sedangkan orange yang menunjukkan nilai $42 \mathrm{~cm} / \mathrm{s}^{2}$ hingga $52 \mathrm{~cm} / \mathrm{s}^{2}$ berada pada barat laut dan timur laut dari daerah penelitian. Nilai indeks kerentanan tanah yang tergolong rendah ditandai dengan warna biru tua. Hal ini menunjukkan bahwa nilai kerentanan tanah didaerah penelitian tergolong masih wajar atau rendah yang diliat dari persebaran warna biru di hamper seluruh wilayah penelitian.

Nilai indeks keretanan tanah juga bergantung pada kondisi geologi pada daerah penelitian. Penelitian ini mempunyai indeks kerentanan seismic yang bervariasi. Kerentanan seismic tinggi yaitu $>20$, sedangkan 4-20 tergolong sedang dan indeks kerentanan kecil <4. Diketahui bahwa daerah Surabaya didominasi dengan alluvial, sehingga dengan tipe batuan sedimen seperti itu untuk nilai 4 $\mathrm{cm} / \mathrm{s}^{2}$ hingga $20 \mathrm{~cm} / \mathrm{s}^{2}$ memungkinkan terjadinya 
resiko yang disebabkan oleh gempa bumi dari kedua sesar Surabaya-Kendeng dan Surabaya-Waru karena nilai Kg cenderung tinggi. Namun demikian secara umum daerah penelitian masih tetap stabil secara tanah. Sedangakan untuk nilai Kg yang cenderung kecil berpengaruh dengan karakteristik dinamik tanah yang menunjukkan rendahnya nilai shear strain saat gempa bumi.

\section{Analisa Peak Ground Acceleration (PGA)}

Percepatan tanah maksimum merupakan dampak gelombang gempabumi di lokasi pengukuran, sehingga dari nilai yang didapatkan dalam pengolahan data dapat dijadikan ukuran intensitas gempabumi yang dialami didaerah penelitian bila nanti terjadi gempa bumi yang disebabkan sesar Kendeng.

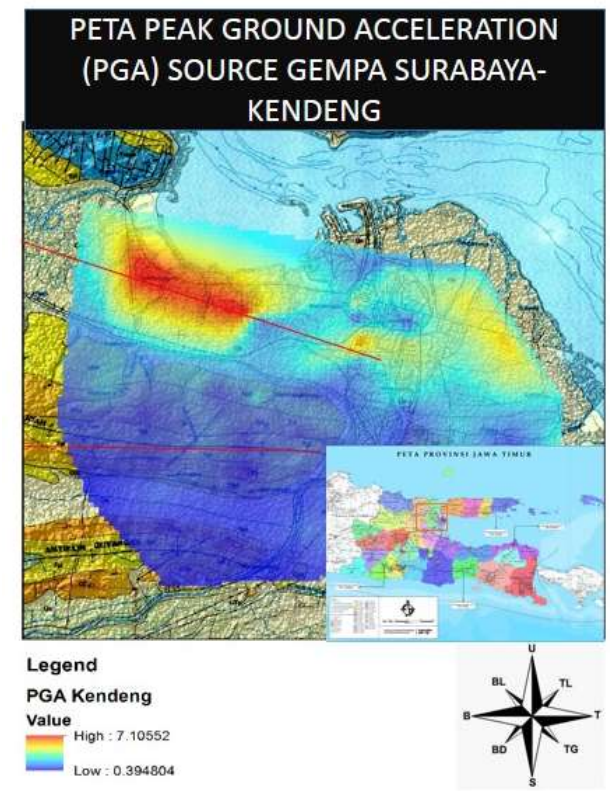

Gambar 5. Peta Peak Ground Acceleration (PGA) pada sumber gempa Surabaya-Kendeng

Berdasarkan peta 5 didapatkan nilai PGA setelah dilakukan pembobotan sebesar 0.6 dan 0.4 adalah $0.2 \mathrm{~g}$ hingga $4.3 \mathrm{~g}$. Sedangkan nilai rata-rata berada pada nilai 0.9g. Nilai tertinggi ditandai dengan warna merah yang posisinya tepat pada sesar SurabayaKendeng. Nilai yang cenderung besar tersebut dipengaruhi oleh factor jarak. Titik pengukuran yang menghasilkan nilai tinggi tersebut adalah titik T15 dengan $R$ atau jarak sebesar $0.62 \mathrm{~km}$. Untuk nilai PGA di batuan dasar didapatkan nilai dalam rentan $0.1 \mathrm{~g}$ sampai $0.9 \mathrm{~g}$ dengan nilai rata-rata diseluruh titik pengukuran adalah sebesar $0.3 \mathrm{~g}$. Nilai ini tergolong meningkat ke arah barat laut dan berkurang selatan.
Pola tersebut disebabkan lokasi titik tertinggi berada pada jarak yang relative dekat dengan sumber gempa atau dengan sesar Surabaya-Kendeng. Semakin mendektai sesar, maka nilai PGA cenderung semakin naik. Berdasarkan besar magnitude 4.6 dan dengan nilai PGA yang didapatkan dalam pengolahan data menghasilkan skala goncangan di permukaan tergolong dalam skala IV-VIII dengan gempa yang dapat dirasakan tergolong besar atau violent.

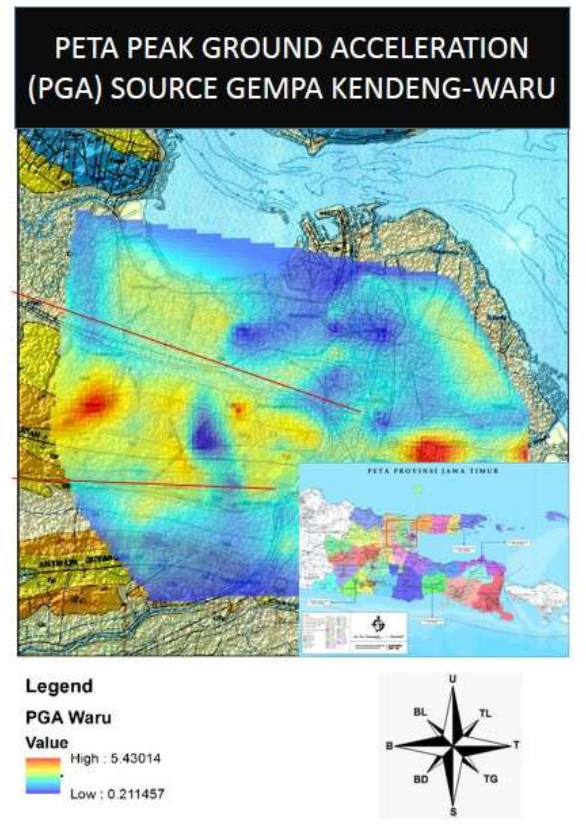

Gambar 6. Peta Peak Ground Acceleration untuk sumber gempa Surabaya-Waru

Berdasarkan hasil yang didapatkan berdasarkan batuan dasar, nilai PGA sebesar $0.13 \mathrm{~g}$ hingga $0.9 \mathrm{~g}$. Sedangkan nilai PGA permukaan yang didapatkan dari perkalian dengan amplifikasi (AO) yaitu didapatkan nilai PGA sebesar $0.2 \mathrm{~g}$ hingga $3.4 \mathrm{~g}$. Nilai PGA yang dihasilkan adalah hasil dari pembobotan yang dilakukan melalui metode logic tree berdasarkan model fault atau sesar. Besar nilai magnitude yang digunakan sebesar 5.6 yang dihasilkan dari konversi nilai $\mathrm{Mw}$ yang didapatkan dari update peta sesar Indonesia 2016.

Dari persebaran nilai yang didapatkan dan telah di overlay pada peta geologi, didapatkan nilai terbesar yang ditandai dengan warna merah yang bahkan cenderung menjauhi kedua sesar. Hal ini dapat saja terjadi sebagai akibat dari pengaruh jarak. Nilai yang mendominasi ditunjukkan dengan warna kuning hingga biru tua yang persebarannya merata 
sejajar dengan kedua sesar. Namun pada sesar Surabaya-Waru tidak memunculkan nilai PGA yang tinggi, bahkan tergolong rendah. $\mathrm{Hal}$ ini berkebalikan dengan hasil PGA yang didapatkan pada pengukuran sumber gempa sesar SurabayaKendeng. Sehingga dapat disimpulkan bahwa daerah yang lebih rawan bencana apabila terjadi gempa bumi dengan sumber gempa Surabaya-Waru maka daerah yang paling rawan adalah daerah selatan sesar Surabaya-Kendeng. Berdasarkan nilai PGA yang didapatkan, nilai tersebut tergolong dalam instrumental intensity skala VI-VIII dengan kekuatan goncangan dalam kategori strong hingga very strong.

\section{PENUTUP}

\section{Kesimpulan}

Kesimpulan yang didapat dari penelitian ini antara lain.

1. Didapatkan nilai frekuensi dominan yang adalah berkisar dari $0.8 \mathrm{~Hz}$ hingga $5.1 \mathrm{~Hz}$. Nilai frekuensi yang mendominasi ada sekitar $1.1 \mathrm{~Hz}$ hingga $2.8 \mathrm{~Hz}$. Nilai fo yang berada pada rentan nilai $3.6 \mathrm{~Hz}$ hingga $4.4 \mathrm{~Hz}$ merupakan nilai yang tergolong tinggi, rentan nilai tersebut berada pada antara sesar Surabaya-kendeng dan Surabaya-Waru.

2. Didapatkan nilai Ao atau amplifikasi berada pada rentan nilai $1.1-8.7$. Nilai tertinggi adalah sebesar $60 \mathrm{~cm} / \mathrm{s}^{2}$ yaitu pada titik T19. Nilai yang dihasilkan berkisar antara 1.5 - 4 dapat diklasifikasikan tergolong pada zona 2 yaitu pada rentan $3 \leq A<6$ yaitu pada kategori sedang.

3. Didapatkan nilai tertinggi adalah sebesar 60 $\mathrm{cm} / \mathrm{s}^{2}$ yaitu pada titik T19 yang ditunjukkan dengan warna merah pekat. orange yang menunjukkan nilai $42 \mathrm{~cm} / \mathrm{s}^{2}$ hingga $52 \mathrm{~cm} / \mathrm{s}^{2}$ berada pada barat laut dan timur laut. Maka diketahui bahwa nilai kerentanan tanah didaerah penelitian tergolong masih wajar atau rendah.

4. Pada sumber gempa Surabaya-Kendeng nilai PGA didapatkan nilai $0.2 \mathrm{~g}$ hingga $4.3 \mathrm{~g}$. Nilai tertinggi ditandai dengan warna merah yaitu titik T15. Untuk nilai PGA di batuan dasar didapatkan nilai dalam rentan $0.1 \mathrm{~g}$ sampai $0.9 \mathrm{~g}$. Tergolong dalam skala IV-VIII dengan gempa yang dapat dirasakan tergolong besar atau violent.
5. Pada sumber gempa Surabaya-Waru hasil yang didapatkan berdasarkan batuan dasar, nilai PGA sebesar 0.13 g hingga 0.9 g. Sedangkan nilai PGA permukaan didapatkan nilai PGA sebesar $0.2 \mathrm{~g}$ hingga $3.4 \mathrm{~g}$. Tergolong dalam instrumental intensity skala VI-VIII dengan kekuatan goncangan dalam kategori strong hingga very strong.

\section{Saran}

Saran yang dapat diberikan berdasarkan hasil dan kesimpulan untuk membangun hipotesa-hipotesa selanjutnya antara lain.

1. Untuk penelitian selanjutnya disarankan menambahkan titik pengukuran mulai dari sesar kecil maupun sesar besar sampai atau seluruh sesar yang berada di wilayah Surabaya.

2. Untuk pengembangan penelitian analisis seismic hazard selanjutnya perlu dilakukan pemodelan untuk membuat satuan geomorfologi yang cocok untuk Indonesia khususnya Surabaya berdasarkan ketersediaan data geologi dan morfologi Indonesia.

3. Perlu dilakukan penelitian lebih lanjut mengenai fungsi atenuasi dan persamaan geomorfologi yang lebih tepat diterapkan untuk daerah Surabaya.

\section{Ucapan Terima Kasih}

Penulis mengucapkan terima kasih kepada dosen- dosen pembimbing bapak Singgih dan Bapak Amien Widodo, atas ide penulisan dan pengarahannya selama proses penelitian hingga penulisan laporan penelitian.

\section{DAFTAR PUSTAKA}

Abu, Bakri. (2014). Analisis Ground Shear Strain dengan Metode HVSR Di Kabupaten Kulonprogo Daerah Istimewa Yogyakarta. Yogyakarta: Universitas Negeri Yogyakarta.

Dewi A, Yustina. (2016). Mikrozonasi Indeks Kerentanan Tanah di Kawasan Jalur Sesar Opak Berdasarkan Pengukuran Mikrotremor. (Skripsi), Universitas Negeri Yogyakarta, Yogyakarta.

Daryono. (2013) Indeks Kerentanan Tanah Berdasarkan Mikrotremor pada Setiap Satuan Bentuk lahan di 
Zona Graben Bantul, Daerah Istimewa Yogyakarta. Jurnal Riset Daerah Vol. XII, No.1. April 2013

Edwiza, Daz \& Sri Novita. (2008). Pemetaan Percepatan Tanah Maksimum dan Intensitas Tanah Kota Padang Panjang Menggunakan Metoda Kannai. Padang: Repository Universitas Andalas.

Laberrta, 2013, Mikrozonasi indeks kerentanan tanah berdasarkan analisis mikrotremor di kecamatan Jetis. (Skripsi), Universitas Negri Yogyakarta, Yogyakarta.

Marsyelina, Merizka. (2014). Karakteristik Mikrotremor Dan Seismitas Pada Jalur Sesar Opak, Kabupaten Bantul, Yogyakarta. Skripsi. Yogyakarta: UNY.

Partono, Windu, Masyur Irsyam, Sri Prabandiyani. R W. (2013). Aplikaso Metode HVSR pada Perhitungan Faktor Amplifikasi Tanah di Kota Semarang. Jurnal Ilmu dan Terapan Bidang Teknik Sipil.

Refrizon, dkk. (2013). Analisis Percepatan Getaran Tanah Maksimum dan Tingkat Kerentanan Tanah Daerah Ratu Agung Kota Bengkulu. Prosding Semirata: Universitas Lampung.

Saaduddin, Sismanto, Marjiyono. (2015). Pemetaan Indeks Kerentanan Tanah Kota Padang Sumatera Barat dan Korelasinya dengan Titik Kerusakan Gempabumi 30 September 2009. Yogyakarta: Proceeding, Seminar Nasional Kebumian ke-8.

SESAME European Research Project. (2004). Guidelines for The Implementation of the H/V Spectral Ratio Technique on Ambient Vibration: Measurements, Processing and Interpretation.

Syaifuddin F, Bahri A S, Lestari W and Pandu J 2016 Microtremor study of Gunung Anyar mud volcano, Surabaya, East Java AIP Conference Proceedings 17300500042016

Winoto, Prasetyo. (2010). Analisis Mikrotremor Kawasan Universitas Brawijaya Berdasarkan Metode HVSR. Thesis. Malang : Universitas Brawijaya. 